ISSN 2466-2232

Online ISSN 2466-2100

\title{
$\mathrm{SiC}$ Device와 ZTA $\mathrm{AMB}$ 기판 적용 파워모듈의 무가압 Silver Sintering 접합특성
}

\author{
김 미 송* ·오 철 민 \\ *전자부품연구원 융복합전자소재연구센터
}

\section{Pressureless Silver Sintering Property of SiC Device and ZTA AMB Substrate for Power Module}

\author{
Mi-Song Kim*, Chulmin Oh*, and Won Sik Hong*, \\ *Electronic Convergence Materials \& Device Research Center, Korea Electronics Technology Institute, \\ Gyeonggi-do, 13509, Korea
}

†Corresponding author : wshong@keti.re.kr

(Received March 26, 2019 ; Revised April 10, 2019 ; Accepted April 11, 2019)

\begin{abstract}
We have developed pressureless silver sintering module using zirconia toughened alumina (ZTA) substrate made of active metal brazing (AMB) and SiC device for power module. The silver paste was printed with a metal mask of 80,120 , and $150 \mu \mathrm{m}$ thickness, respectively. The void content was measured by x-ray images after pressureless silver sintering under a vacuum and nitrogen atmosphere. In order to evaluate the durability against thermal stress of the sintered module, the thermal cycle test (TC) and the high temperature storage test (HTS) were conducted. The void content and bond strength before and after the environment test were measured. As a result, the void content did not change, but the bonding strength was decreased after TC and increased after HTS. Crack was generated at between silver sintered joint and ZTA substrate after TC test. Also, we observed that $\mathrm{Cu}-\mathrm{Ag}$ alloy layer was formed between the copper AMB and silver sintered layer after HTS, which finally leaded to improve the bonding strength.
\end{abstract}

Key Words : Power module, Silver paste, Pressureless, Silver sintering, Bonding strength, Interface

\section{1. 서 론}

친환경 자동차 및 신재생 에너지에 대한 요구가 증가 되면서 고출력/고효율 파워모듈의 필요성이 극대화되고 있다. 파워모듈의 출력 향상을 위해 기존 실리콘(silicon, $\mathrm{Si}$ ) 디바이스 보다 에너지 밴드 갭이 넓은(wide band gap, $\mathrm{WBG}$ ) 실리콘 카바이드(silicon carbide, $\mathrm{SiC}$ ) 디바 이스가 적용되고 있으며, 출력 손실을 최소화하는 고효 율 파워모듈 패키지 기술이 요구되고 있다. $\mathrm{SiC}$ 디바이스 파워모듈은 기존 $\mathrm{Si}$ 디바이스보다 정션 온도 (junction temperature, $\mathrm{T}_{\mathrm{J}}$ )가 매우 높기 때문에 패키지 내의 열 전도율을 높이고, 열적 스트레스에 대한 저항성을 향상
시키는 기술이 필요하다 ${ }^{1-4)}$.

파워모듈에서 발생되는 열을 가장 직접적으로 받는 열 영향부는 디바이스의 접합부이므로 $\mathrm{SiC}$ 접합부의 신뢰 성을 향상시키는 것이 매우 중요하다. 전자 및 자동차 전장제품에 사용되는 패키지의 디바이스 접합재료는 주 로 $\mathrm{Sn}$ 계 솔더(solder)가 적용 된다 ${ }^{5-7)}$. 하지만 $\mathrm{SiC}$ 디바 이스의 정션온도는 $300{ }^{\circ} \mathrm{C}$ 이상까지 상승되기 때문에 용융온도가 $230{ }^{\circ} \mathrm{C}$ 내외인 주석(tin, $\mathrm{Sn}$ )계 솔더 재료 는 $\mathrm{SiC}$ 디바이스 모듈에서 매우 취약하다. 따라서 대체 접합재료로 금(gold, $\mathrm{Au}$ )계 고온 솔더나 은(silver, $\mathrm{Ag}$ ) 소결(sintering) 접합방법이 적용되고 있다. 기존 소결 기술은 융점 이하의 온도에서 압력을 가해 고상 결합하 는 기술이며, 현재 상용화된 $\mathrm{Ag}$ 페이스트는 공정 온도 
Table 1 Mechanical characteristics of various ceramic substrate materials

\begin{tabular}{|c|c|c|c|c|}
\hline Characteristics & $\mathrm{Al}_{2} \mathrm{O}_{3}$ & $\mathrm{AlN}$ & $\mathrm{ZTA}$ & $\mathrm{Si}_{3} \mathrm{~N}_{4}$ \\
\hline $\begin{array}{c}\text { Thermal conductivity } \\
{[\mathrm{W} / \mathrm{mK}]}\end{array}$ & 24 & 180 & 28 & 90 \\
\hline $\begin{array}{c}\text { Bending strength } \\
{[\mathrm{MPa}]}\end{array}$ & 450 & 450 & 700 & 650 \\
\hline Fracture toughness & $3.8-4.2$ & $3-3.4$ & $4.5-5$ & $6.5-7$ \\
\hline
\end{tabular}

가 약 $250{ }^{\circ} \mathrm{C}$ 내외로 $\mathrm{Ag}$ 융점보다 현저히 낮은 온도 에서 접합할 수 있다. 또한 $\mathrm{SiC}$ 디바이스의 구동온도인 $300{ }^{\circ} \mathrm{C}$ 이상에서도 재용융 되지 않기 때문에 $\mathrm{SiC}$ 디바 이스 파워모듈용 칩 접합방법으로 가장 유력한 대체 공 법 중 하나이다.

모듈의 기판은 direct bonded copper $(\mathrm{DBC})$, active metal brazing(AMB) 공법으로 주로 제조되며, 세라 믹의 양면에 구리 $(\mathrm{Cu})$ 박판(foil)이 접합된 구조를 갖 는다. Table 1은 파워모듈 기판으로 주로 사용되는 세라 믹 재질의 특성을 나타냈다. 세라믹 재질에 따라 모듈의 기계적, 열적 특성이 변할 수 있기 때문에 기판 채택도 매우 중요하다 ${ }^{8-9)}$.

본 연구에서는 기계적 강도 특성이 우수한 zirconia toughened alumina(ZTA) AMB 기판을 채택하였고, $300{ }^{\circ} \mathrm{C}$ 이상의 구동온도에 적용 가능한 $\mathrm{Ag}$ 소결 기술 을 적용한 $\mathrm{SiC}$ 파워모듈을 제작하여 $\mathrm{Ag}$ 소결 접합부의 열적 스트레스에 대한 내구성을 평가하였다.

\section{2. 실험 방법}

\section{1 무가압 $\mathrm{Ag}$ 소결 접합공정을 이용한 모듈 제작}

무가압(pressureless) $\mathrm{Ag}$ 소결 접합공정을 위해 사 용된 기판은 ZTA 재질의 세라믹 양면에 $\mathrm{Cu}$ 층이 브레 이징 된 $\mathrm{AMB}$ 기판을 사용하였다. 기판의 표면처리는 $\mathrm{Cu}$ 표면을 사용하기 위해 organic solderability preservative(OSP) 표면처리 된 기판을 사용하였다. 더미 칩 (dummy chip)은 실제 전력변환모듈에 널리 쓰이는 Cree사의 실제 구동 칩(live chip)과 동일한 크기의 $4.04 \times 6.44 \mathrm{~mm}, \mathrm{t}=180 \mu \mathrm{m}$ 로 제작하였다. $\mathrm{SiC}$ 더미 칩의 상면과 하면에는 각각 $\mathrm{Al}$ 과 $\mathrm{Ni} / \mathrm{Ag}$ 로 박막 증착한 후 접합공정에 사용하였다.

$\mathrm{Ag}$ 소결 접합에 사용된 $\mathrm{Ag}$ 페이스트는 교세라 $(\mathrm{CT}-$ 2700R7S, Kyocera Co., Ltd., 일본) 상용 제품을 사용하 였다.

$\mathrm{Ag}$ 페이스트의 프린팅 공정을 위해 메탈 마스크(metal mask)를 $\mathrm{SiC}$ 더미 칩 크기에 맞게 각각 80,120 , (a)

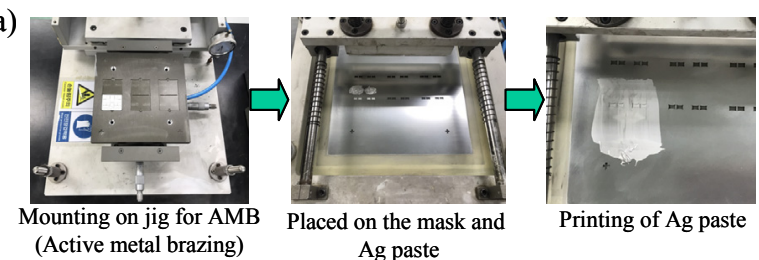

(b)

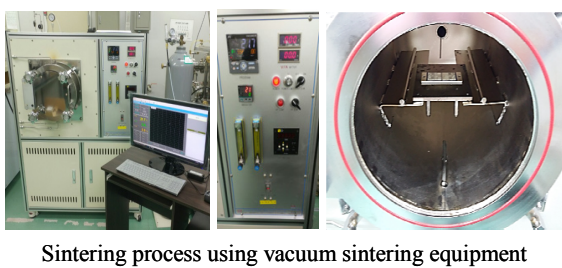

(c)

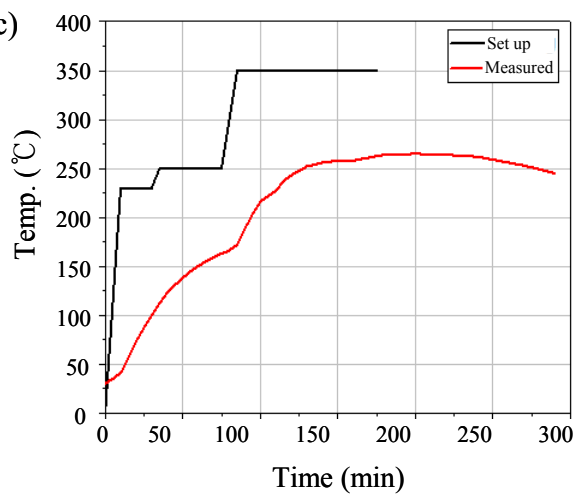

Fig. 1 Photographs of (a) silver paste printing process, (b) vacuum sintering machine and (c) sintering temperature profile

$150 \mu \mathrm{m}$ 두께로 제작하였다. 또한 메탈마스크 두께에 따 른 $\mathrm{Ag}$ 접합부의 보이드 분율의 차이를 비교분석 하였다. 무가압 소결 공정은 Fig. 1(a)과 같이 프린팅 장비 지그에 $\mathrm{AMB}$ 기판을 고정시킨 후 메탈 마스크의 위치 를 맞추고, $\mathrm{Ag}$ 페이스트를 마스크에 도포 후 프린팅 하 였다. $\mathrm{Ag}$ 페이스트가 프린팅된 $\mathrm{AMB}$ 기판위에 $\mathrm{SiC}$ 더 미 칩을 마운팅(mounting) 한 후 무가압 소결 접합공 정을 진행하였다. 소결 접합공정은 Fig. 1(b)의 진공 소결장비를 이용하여 진공 분위기 조성 후 질소 $\left(\mathrm{N}_{2}\right)$ 가 스를 지속적으로 주입하면서 Fig. 1(c)의 온도 프로파일 조건으로 진행하였다. 소결 공정은 최고 온도 $250{ }^{\circ} \mathrm{C}$ 에 서 $165 \mathrm{~min}$ 동안 진행하였다. Fig. 2는 $\mathrm{Cu} \mathrm{AMB}$ 기 판 및 더미 칩을 이용한 무가압 $\mathrm{Ag}$ 소결 접합공정 후 시편 사진이다.

\section{2 소결 접합부 열화 특성 분석}

무가압 $\mathrm{Ag}$ 소결 접합 공정을 이용한 모듈의 열적 스트 레스에 대한 내구성평가를 위해 열사이클시험(thermal cycling test, TC) 및 고온방치시험(high temperature storage test, HTS)을 진행하였다. 열사이클시 험은 $\mathrm{ESPAC}$ 사의 TSA-11A 열충격시험기를 이용하였 


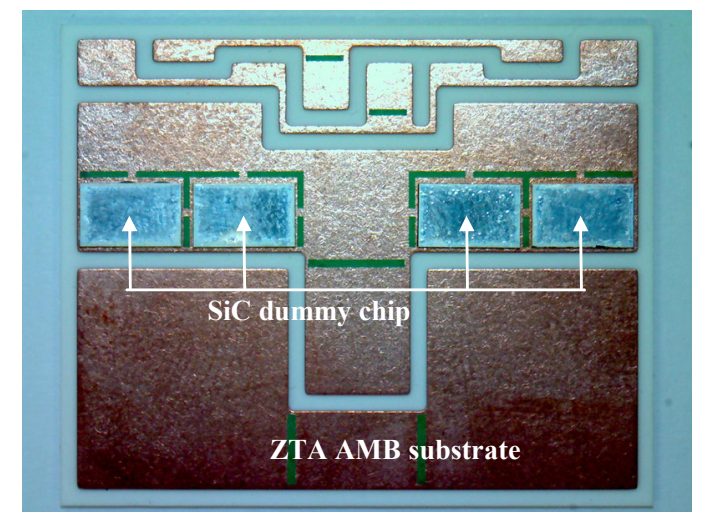

Fig. 2 Optical micrograph of $\mathrm{Cu} \mathrm{AMB} / \mathrm{SiC}$ dummy chip module after silver sintering

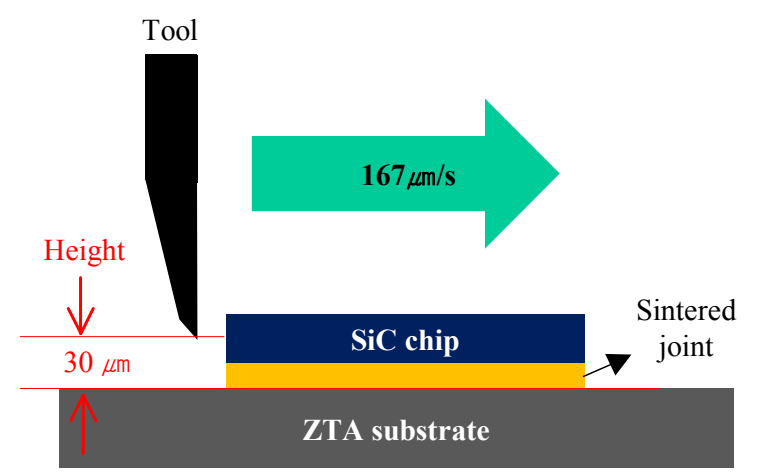

Fig. 3 Schematic diagram of chip/AMB shear strength test
고, $-50 \sim 150{ }^{\circ} \mathrm{C}$, 유지시간 $10 \mathrm{~min}$ 으로 500 cycles 동 안 진행하였다. 고온방치시험은 JEIO Tech사의 $5 \mathrm{~F}-22 \mathrm{GW}$ 오븐을 이용하였고, $200{ }^{\circ} \mathrm{C}$ 에서 $500 \mathrm{~h}$ 방치한 후 칩 접 합부의 열화특성을 측정하였다.

\section{$2.3 \mathrm{Ag}$ 소결 접합 특성 평가}

환경시험 전후 소결 접합부 특성 평가를 위해 보이드 분율 및 접합강도를 측정하였다. 보이드 분율은 X-ray 비파괴분석 장비를 이용하여 칩 접합면적 대비 보이드 면적 비율을 분율로 나타내었다. 접합강도는 Dage사의 Dage4000 장비를 이용하였고, 측정 조건은 전단지그 높이 $30 \mu \mathrm{m}$, 시험 속도 $167 \mu \mathrm{m} / \mathrm{s}$ 로 측정하였다(Fig. 3).

환경시험 전후 소결 접합부의 미세조직 특성평가를 위 해 단면분석을 진행하였다. $\mathrm{AMB}$ 기판/칩의 $\mathrm{Ag}$ 소결 접합 부 단면 연마 후 scanning electron microscope (SEM) 분석을 진행하였다.

\section{3. 실험 결과}

\section{1 메탈 마스크 두께에 따른 접합부 보이드}

프린팅 공정에 사용되는 메탈 마스크 두께에 대한 보 이드 함량의 영향을 분석하기 위해 메탈 마스크 두께를 각각 $80,120,150 \mu \mathrm{m}$ 를 사용하여 프린팅 한 후 소결

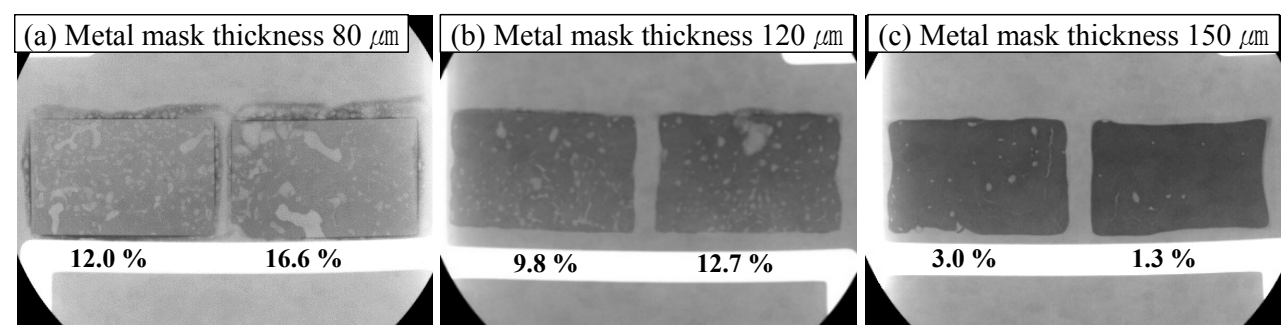

(d)

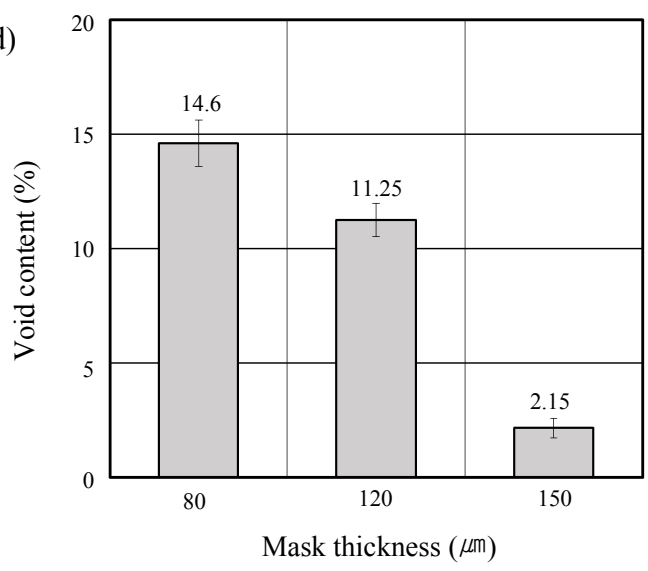

Fig. 4 (a-c) X-ray non-destructive analysis result after silver sintering and (d) void content measurement results with mask thickness 


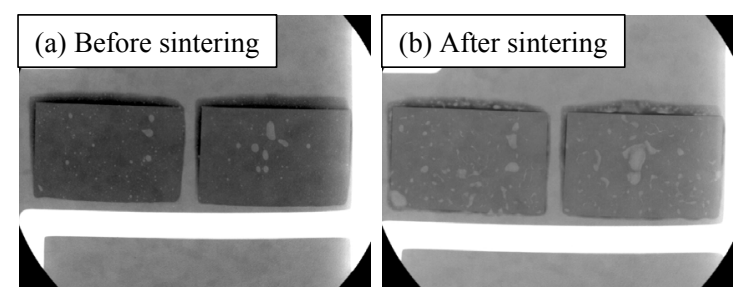

(c)

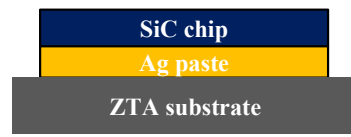

(d)

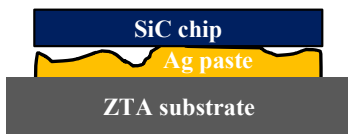

Fig. 5 Comparison of void content (a) before / (b) after sintering using by X-ray non-destructive analysis, Schematic diagram of printing result of (c) uniform and (d) irregular printed layers

접합부의 보이드 분율을 Fig. 4 와 같이 비교하였다. 그 결과 마스크 두께가 두꺼울수록 보이드 분율이 낮게 나 타난 것을 알 수 있었다.

$\mathrm{Ag}$ 페이스트 프린팅 및 소결 공정 후 접합부 보이드 에 대한 X-ray 분석 사진을 Fig. 5에 나타냈다. 프린 팅 공정 중 형성된 내부 보이드는 소결 후 보이드의 크 기가 증가되는 것으로 관찰되었다. 프린팅 공정 중 도 포된 $\mathrm{Ag}$ 페이스트의 두께 균일도가 불균일할 경우, 칩 과 $\mathrm{Ag}$ 페이스트 접촉면에서 발생되는 공간으로 인해

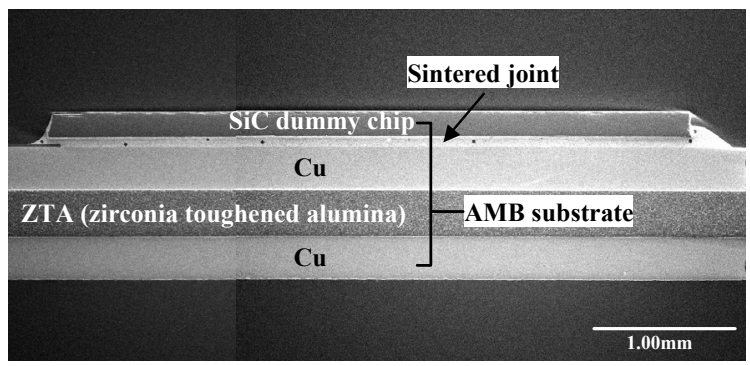

Fig. 6 Cross-sectional SEM micrograph of SiC device/ ZTA AMB substrate after pressureless silver sintering

기포가 형성되며, 소결 이후에 지속적으로 잔존하게 되 어 보이드 함유율이 증가되는 것으로 사료된다. 따라서 프린팅 공정 중 발생되는 보이드를 최소화 하는 것이 매우 중요하며, 보이드 함유량이 가장 많았던 $80 \mu \mathrm{m}$ 두 께의 메탈 마스크는 프린팅 공정에 적합하지 않은 것으 로 최종 판단하였다.

\section{2 환경시험 전후 접합부 특성변화}

Fig. 6은 무가압 $\mathrm{Ag}$ 소결 접합 후 초기 시편의 단면 분석 한 결과이며, $\mathrm{AMB}$ 기판 위에 $\mathrm{SiC}$ 더미 칩이 매 우 균일하게 접합된 것을 확인하였다.

Fig. 7은 환경시험 전후의 광학현미경 및 X-ray, 단

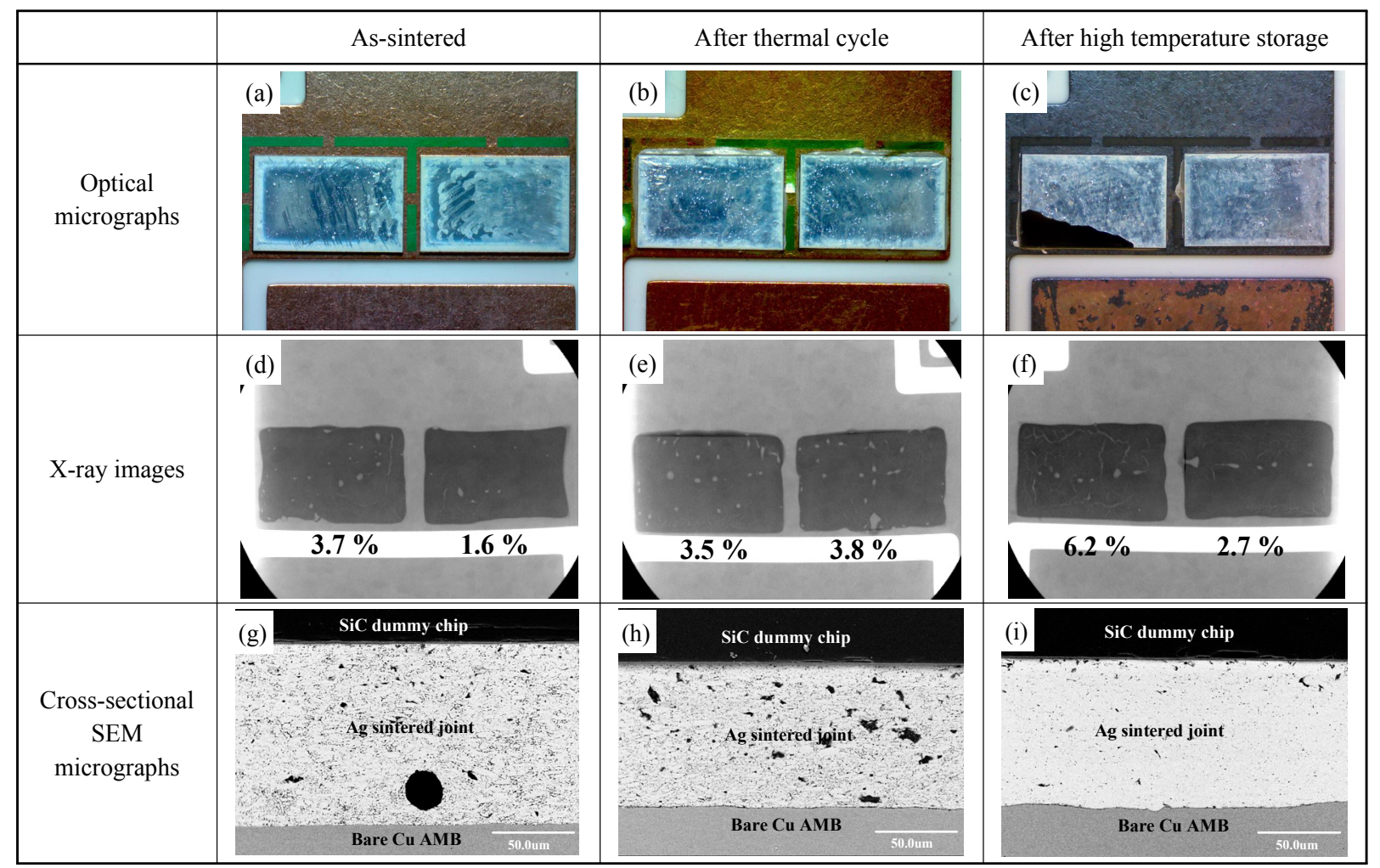

Fig. 7 (a-c) Optical micrographs, (d-f) X-ray non-destructive analysis results and (g-i) cross-sectional SEM micrographs of pressureless silver sintered joints before/after thermal cycling test and high temperature storage test 


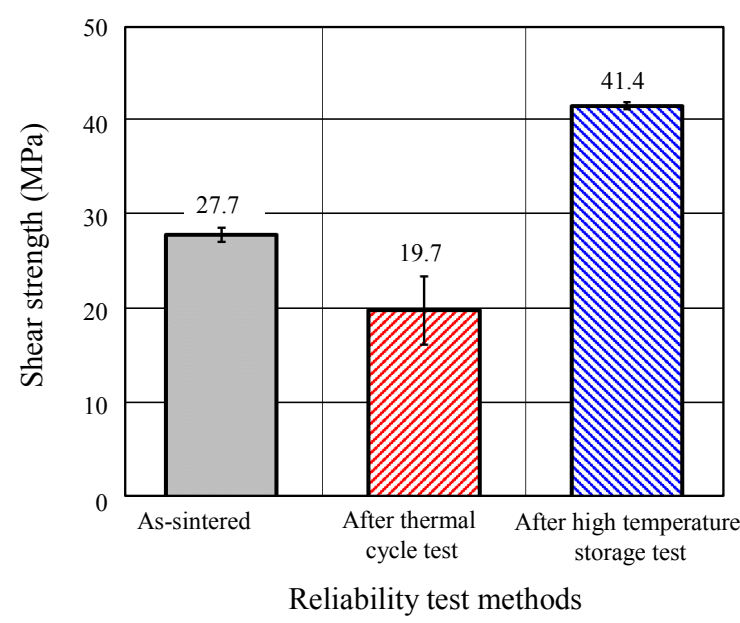

Fig. 8 Bonding strength comparison with before/after reliability tests
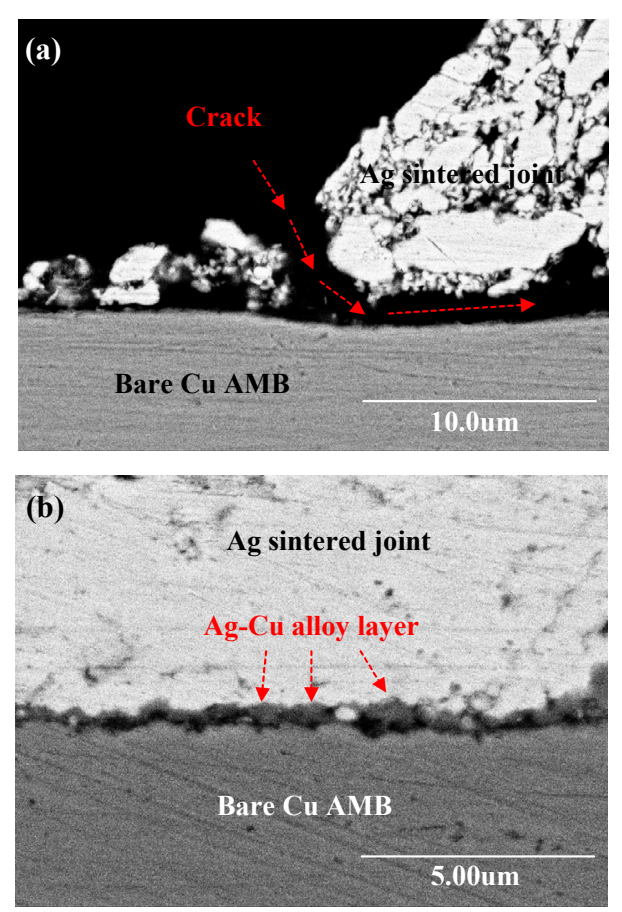

Fig. 9 Cross-sectional SEM micrographs of (a) after thermal cycle test and (b) after high temperature storage test

면 $\mathrm{SEM}$ 분석 결과를 나타냈다. 분석결과 $\mathrm{AMB}$ 기판 의 $\mathrm{Cu}$ 표면이 $\mathrm{TC}$ 및 $\mathrm{HTS}$ 후 시편 표면에서 각각 황 색 및 적색을 띄며 산화되었고, HTS 시편에서는 열적 스트레스에 의해 더미 칩 상부의 증착된 $\mathrm{Al}$ 층이 박리 된 것을 확인하였다. 환경시험 전후 각 시편의 보이드 함유량은 변화가 없었다. 소결 접합부의 $\mathrm{Ag}$ 소결 입자 (particle) 충진 정도를 비교해 보면, HTS 후 충진 정 도가 더욱 조밀해졌고, $\mathrm{TC}$ 후에는 열적 스트레스에 의 해 초기 대비 micro crack이 소결 접합부에 형성된 것 이 관찰되었다. 이러한 micro crack은 소결과정 중
$\mathrm{Ag}$ 입자간 네트워킹이 충분히 형성되지 않은 부위에서 주로 발생되는 것으로 보인다.

전단강도시험 결과 $\mathrm{Fig}$. 8과 같이 $\mathrm{Ag}$ 소결 접합강도 는 $27.7 \mathrm{MPa}$ 로 측정되었고, $\mathrm{TC}$ 후 $19.7 \mathrm{MPa}$ 로 초기 강도 대비 약 0.7 배로 감소하였다. 반면, HTS 후에는 $41.4 \mathrm{MPa}$ 로 초기강도 대비 약 1.5 배 증가한 것을 알 수 있었다. Fig. 9 (a)는 TC 후 접합부의 SEM 단면 분석 결과이다. $\mathrm{Ag}$ 접합부 끝부분에서 발생한 crack이 $\mathrm{Cu} \mathrm{AMB} / \mathrm{Ag}$ 접합계면을 따라 진전하여 균열을 유발 한 것이 관찰되었다. 또한, Fig. 9 (b)에서 HTS 후 $\mathrm{Cu} \mathrm{AMB} / \mathrm{Ag}$ 접합부의 상호확산 반응으로 인해 $\mathrm{Cu}-\mathrm{Ag}$ alloy 층이 미세하게 형성된 것이 관찰되었고, 이러한 $\mathrm{Cu}-\mathrm{Ag}$ alloy 층은 소결 접합부의 접합강도 향상에 기 여한 것으로 보인다.

\section{4. 결 론}

본 연구에서는 무가압 $\mathrm{Ag}$ 소결 접합 공정을 적용하 여 $\mathrm{SiC}$ 디바이스와 $\mathrm{ZTA} \mathrm{AMB}$ 기판을 이용한 파워모 듈을 개발하였으며, 그 결과는 다음과 같다.

1) 메탈 마스크 두께에 따른 보이드 분율을 비교분석 한 결과, $150 \mu \mathrm{m}$ 메탈 마스크를 적용한 시편에서 보이 드 분율이 약 $2.15 \%$ 로 가장 적게 나타났다.

2) 열사이클시험 후 $\mathrm{Ag}$ 소결 접합부에서 발생된 crack은 $\mathrm{ZTA} \mathrm{AMB}$ 와 소결된 $\mathrm{Ag}$ 계면을 따라 접합부 내부로 진 전되며 균열을 유발한 것이 관찰되었고, 이로 인해 접합 강도가 초기대비 약 0.7 배 수준으로 감소된 것을 알 수 있었다.

3) 고온방치시험 후 소결 접합부의 접합강도는 초기 대비 1.5 배 증가하였다. 이것은 접합계면의 $\mathrm{Cu}-\mathrm{Ag}$ alloy 층 형성과 고온 분위기 하에서 $\mathrm{Ag}$ 입자간 소결이 지속적으로 유발되어 소결부의 충진 밀도가 증가되었기 때문인 것으로 판단된다.

$$
\text { 후기 }
$$

본 연구는 산업통상자원부 첨단뿌리기술분야 산업핵 심기술개발사업(과제번호: 10063263)의 지원을 받아 수 행된 연구결과입니다.

ORCID: Mi-Song Kim: http://orcid.org/0000-0002-4717-9365 ORCID: Chulmin Oh: http://orcid.org/0000-0003-4609-9408

ORCID: Won Sik Hong: http://orcid.org/0000-0001-8398-177X

\section{References}

1. Jeong-Won Yoon, Jung-Hwan Bang, Yong-Ho Ko, SeHoon Yoo, Jun-Ki Kim and Chang-Woo Lee, Power Module Packaging Technology with Extended Reliability 
for Electric Vehicle Applications, Journal of Microelectron. Package. Soc., 21(4) (2014), 1-13

http://doi.org/10.6117/kmeps.2014.21.4.001

2. Won Sik Hong, Mi Song Kim, Dajung Kim and Chulmin Oh, Silver Sintered Joint Property Between Silicon Carbide Device and Ceramic Substrate for Electric Vehicle Power Module, Journal of Electronic Materials, 48(1) (2019), 122-134 https://doi.org/10.1007/s11664-018-6769-5

3. Ji-Yeon Park, Chulmin Oh, Deok-Hee Won and Won Sik Hong, Ultrasonic Bonding Property of Aluminum Wire for Power Conversion Module of Automotive, Journal of Welding and Joining, 36(3) (2018), 57-64 https://doi.org/10.5781/JWJ.2018.36.3.9

4. Junhyuk Son, Minkyung Kim, Dong-Yurl Yu, Young-Ho Ko, Jeong-Won Yoon, Chang-Woo Lee, Young-Bae Park and Junghwan Bang, Thermal Aging Characteristics of $\mathrm{Sn}-\mathrm{xSb}$ Solder for Automotive Power Module, Journal of Welding and Joining, 35(5) (2017), 38-47 https://doi.org/10.5781/JWJ.2017.35.5.6

5. Won Sik Hong, Chulmin Oh, Mi-Song Kim, Young Woo Lee, Hui Joong Kim, Sung Jae Hong and Jeong Tak Moon,
$\mathrm{Al}$ and Si Alloying Effect on Solder Joint Reliability in Sn-0.5Cu for Automotive Electronics, Journal of Electronic Materials, 45(12) (2016), 6150-6162

https://doi.org/10.1007/s11664-016-4837-2

6. A Young Kim and Won Sik Hong, Degradation Charac- teristics of Eutectic and Pb-free Solder Joint of Electronics mounted for Automotive Engine, Journal of Welding and Joining, 32(3) (2014), 74-80

https://doi.org/10.5781/JWJ.2014.32.3.74

7. Won Sik Hong and Chulmin Oh, Degradation Behavior of Solder Joint and Implementation Technology for Leadfree Automotive Electronics, Journal of Welding and Joining, 31(3) (2013), 43-50

https://doi.org/10.5781/KWJS.2013.31.3.43

8. Jiri Hlina, Jan Reboun, Martin Hirman and Ales Hamacek, Comparison of Copper and Silver Thick Film on Alumina Substrates Properties, International Spring Seminar on Electronics Technology (ISSE), 40 (2017), 359-365 https://doi.org/10.1109/ISSE.2017.8000882

9. Jurgen Schulz-Harder, Advantages and new development of direct bonded copper substrates, Journal of Microelectronics Reliability, 43 (2016), 359-365 https://doi.org/10.1016/S0026-2714(02)00343-8 